Sensors 2008, 8, 1984-2005

\title{
sensors
}

ISSN 1424-8220

(C) 2008 by MDPI

www.mdpi.org/sensors

Review

\section{Innovative Sensors for Environmental Monitoring in Museums}

\author{
Mauro Bacci*, Costanza Cucci, Andrea Azelio Mencaglia and Anna Grazia Mignani \\ Istituto di Fisica Applicata "Nello Carrara” (IFAC-CNR), 50019 Sesto Fiorentino, Firenze, Italy; \\ Tel.: +39-055-5226370, Fax: +39-055-5226374; E-mails: c. cucci@ifac.cnr.it; \\ a.mencaglia@ifac.cnr.it; a.g.mignani@ifac.cnr.it
}

*Author to whom correspondence should be addressed; E-mail: m.bacci@ifac.cnr.it

Received: 29 January 2008 / Accepted: 18 March 2008 / Published: 22 March 2008

\begin{abstract}
Different physical and chemical factors, such as light, temperature, relative humidity, pollutants and so on, can affect works of art on display. Each factor does not act individually, but its effect can be enhanced or accelerated by the presence of other factors. Accordingly, an evaluation of the impact of the whole environment on art objects is recognized as an essential requirement for conservation purposes. To meet the most up-todate guidelines on preventive conservation, in recent years several scientific projects supported by the EC were aimed at developing innovative tools that could complement the standard methods for environmental monitoring in museums. These research projects produced a new generation of passive sensors that are capable of taking into account the overall environmental effects by mimicking in some way the behaviour of real works of art. The main goal of the present paper is to provide a survey of these sensors, which represent a new frontier in the environmental control in museums. Furthermore, the use of optical fibres, as both intrinsic sensors and devices for interrogating sensors, will also be illustrated, and examples of their use in the cultural heritage field will be reported.
\end{abstract}

Keywords: museum microclimate, environmental sensors, early warning systems, preventive conservation, indoor monitoring.

\section{Introduction}

Objects of art on display in museums, galleries, churches, etc., are affected by environmental physical and chemical factors that can constitute a threat for their conservation and greatly reduce their 
lifespan. Accordingly, continuous control and monitoring are needed in order to contrast the natural decay of the objects, which may be accelerated by adverse environmental conditions due, for instance, to pollution or poor conservation practices.

As early as the second half of the $19^{\text {th }}$ century, awareness arose of the possible alterations that exhibit conditions could induce on the objects on display (Russell-Abney report) [1].

As is well-known, light is one of the primary damage factors: it can produce different effects, such as colour alteration, colour fading, mechanical damage, embrittlement, and so on. Naturally, light is also necessary so that visitors can enjoy works of art; therefore, curators and conservators have to find a compromise to make it possible for visitors to benefit from it while guaranteeing long life for the artefacts.

Other factors that can potentially constitute a threat for works of art are temperature and relative humidity, together with their abrupt changes. In fact, under the effect of temperature the reaction rate of many chemical reactions increases, causing serious structural alterations in objects. Moreover, thermo-hygrometric fluctuations can induce deformations in non-isotropic materials, or detachments of parts consisting of different materials. On the other hand, high humidity can favour micro-organisms and moulds that can attack the supports in which these develop. Moreover, owing to variations in humidity, mechanical changes and deformations can occur in hygroscopic materials, such as wood panels, while hygroscopic hydrated minerals in natural history museums can be altered.

Artefacts can be also seriously damaged by atmospheric pollutants, often also present indoors, such as $\mathrm{NO}_{\mathrm{x}}, \mathrm{SO}_{2}, \mathrm{O}_{3}$, organic vapours and cleaning agents, just to mention a few. These gases can produce not only colour changes, but also corrosion (mainly in metals) and chemical and/or mechanical alterations.

All the above factors act not only individually, but also cooperatively, so that the effect of one factor is enhanced by the presence of others: for example, light and temperature, light and pollutants, pollutants and humidity. In some cases, specific definitions have been introduced to take into account synergistic effects. For example, in referring to light and photo-induced phenomena, we can mention the concept of equivalent light dose. This term is used to define the light dose capable of producing, in a given material exposed to light and other uncontrolled environmental agents, the same effect (e.g. colour change) as the one induced in the same material by exposure to a known light-source and in controlled environmental conditions [2].

To summarize, for a correct conservation policy, it is important not only to monitor the single physical or chemical parameter, but also to evaluate the impact of the whole environment. This is not a simple task. In fact, many devices are available that make it possible to measure temperature/relative humidity (thermo hygrographs), light (lux meters), powders, selected pollutants, etc., separately; however, they are not suitable for assessing the overall actions of these factors. Furthermore, to monitor all the potentially risky factors in a museum environment would necessitate a large set of devices which, apart from the cost in terms of resources and time, would not be acceptable from an aesthetic point of view.

Within this context, in recent decades, increasing interest has been shown in a new generation of sensors, dosimeters, and other devices tailored for applications to the cultural heritage. They consist of smart and low-cost methodologies that are designed to facilitate widespread monitoring and to prevent damaging effects on objects on display. 
Among these new generation sensors, an important role is played by 'impact sensors', which are intended especially for evaluating the cooperative effects of environmental agents. Typically, said impact sensors are dosimeters or passive indicators based on sacrificial materials. They react to the factor to be monitored by displaying an easily measurable change in some specific property. The change in the sensor indirectly indicates the relative strength of the environmental impact of a given agent (or agents). This approach is based on the observation that the work of art itself, which records all the alterations induced by the environment on its surface and its structure, could be viewed paradoxically as an environmental sensor. Naturally, such a solution is unacceptable for ethical reasons, but it could be considered the starting point for a novel concept in monitoring devices, one that exploits the deterioration effect in order to assess the environmental aggressiveness.

In fact, in recent years, different types of sensors have been proposed that mimic in some way the behaviour of an actual object, although in a simplified way and usually with much quicker responses. Indeed, a prompter reaction of the sensor with respect to the material under observation enables curators to identify risky situations before any damage can occur. This is the concept of an 'early warning system', which is of fundamental importance in preventive conservation.

Because of the increasing number of visitors in museums, in recent years the problem of environmental control and safeguarding of objects on display has become more and more pressing, and different solutions have been sought to complement conventional monitoring methodologies.

The aim of this work is to highlight the different approaches and ideas developed for coping with the problem of the environmental impact on artworks exposed to the public. In particular, a review of innovative sensors for environmental control and prevention of damage in museums will be presented, with the focus on selected relevant outcomes of EC research projects specifically devoted to the problem of synergistic environmental effects on artworks.

Section 2 will report on different examples of impact sensors, illustrating various concepts and types of these dosimeters, and their possible applications. Section 3 will be dedicated to devices based on optical-fibre technology. The latter is indeed particularly suitable for museums applications, since optical fibres are not invasive and do not create any visual impact on visitors, owing to their size and characteristics. Furthermore, these sensors are of great interest for museums since they have great potential in terms of remote networks monitoring.

\section{Impact sensors for the museum environment}

"Impact sensors" introduce a novel approach to environmental monitoring in the conservation field. Rather than separately measuring given environmental parameters, these sensors are designed to reproduce, in a very simplified way, the mechanism responsible for alterations observed in the objects on display. Typically, they are passive indicators based on sacrificial materials that react in similar manner to the objects to be surveyed, and undergo some quantifiable change upon exposure to the environment. The said impact sensors are usually disposable, and provide cumulative information, working as dosimeters. They can be designed to monitor either the effects of selected agents (e.g. light, humidity, pollutants, etc.) or cooperative phenomena. Even when these devices are tailored to respond to a selected leading parameter (e.g. light), their response always provides information about the combined effect of this parameter with other agents that can enhance its action. Indeed, the reaction of the sacrificial material is usually additive and non-reversible, thus recording an overall impact. As a 
result, these tools make it possible to assess - and, hence, to prevent - complex deterioration phenomena by means of a simulation principle. This approach appears particularly appealing within the museum context, where various composite objects are exposed simultaneously inside the same environment. The materials constituting an artistic object are extremely varied, and consequently react differently to the environmental conditions [3]. Hence, simple early-warning tools suitable for alerting personnel to risk situations can be helpful for large-scale environmental monitoring. The impact sensors are low-cost, easy-to-read and aesthetically non-invasive. For these reasons, they are being used more and more to complement the conventional approach based on data-logger for environmental monitoring. It should be emphasised that the response of the sensor cannot reproduce the reaction of the real object exactly, but can only simulate some specific phenomenon (e.g. discolouration), in a simplified manner. Consequently, impact sensors will usually provide a semi-quantitative indication, which will then need to be interpreted on the basis of other data. Hence, these sensors are not intended to replace standard instrumentation, which remains the most correct tool for precisely characterising a given micro-environment. Nevertheless, impact sensors are extremely helpful in identifying the presence of complex deterioration phenomena or risk situations that might require a more detailed investigation.

Another important feature of impact sensors is that they can be easily replicated in the desired number of identical specimens. In fact, they are made with low cost sacrificial materials, and are designed to be produced on a large scale. This fact makes it possible to perform several tests of artificial ageing and to study the response of identical replicas under very different environmental conditions. Artificially aged specimens can thus be compared with others that are exposed in real conditions. This comparison is a fundamental strategy for gaining deeper insight into many deterioration phenomena involving artistic materials that are widely recognised as being prone to complex synergistic effects. The following sections will discuss different examples of impact sensors.

\subsection{Against the fading of colours and photo-induced damage: colorimetric sensors}

An important class of passive sensors for museums are those that are based on a colorimetric principle. Their main feature is that they react by displaying a measurable colour change after exposure to the agent(s) to be monitored.

In the field of the cultural heritage, the study of colorimetric variations has always played a fundamental role in diagnosing and characterising artefacts. Indeed, since chromatic alterations are recognised as being among the most serious effects of irreversible deterioration in many works of art, colorimetry was firstly introduced and adopted in conservation science as a tool for quantifying the extent of damage on polychrome surfaces and objects [4-6]. Subsequently, the new concept of exploiting colour variation by itself as an indication of the damage was introduced. Based on this approach, colour changes were used as the working principle of a new generation of sensors for artistic materials. Indeed, colour is both perceived to the naked eye and is measurable with simple instrumentation (portable colorimeters) and non-invasive techniques. It is, therefore, an ideal indicator for passive sensors intended for the cultural heritage.

In recent decades several types of sensors designed to simulate the synergistic processes involved in the deterioration of artworks have been proposed, and have been used to investigate and prevent fading 
and colour alterations in different contexts. Here as follows, with reference to selected meaningful results of EC-funded research projects, different concepts of colorimetric sensors are reviewed:

a) Tempera-based dosimeters, that is, sensors conceived to mimic and to reproduce the behaviour of selected artistic materials in a given environment (EC Projects: "ERA” and "MIMIC”);

b) Early warning systems against photo-induced damage, that is, dosimeters designed so as to react faster than objects on display, in order to give warning of potential risk situations. (EC Project “LiDo”).

\subsubsection{Tempera-based dosimeters}

The ERA Project (Environmental Research for Art Conservation) introduced the idea of studying the microclimate indoor environment of a museum room by means of test panels containing various artistic materials [7]. The panels, which were exposed to the same environment as the artwork, reproduced selected alterations that could be observed in the objects [8-9]. In particular, the focus of the study was on the problem of chromatic alterations occurring on paintings on display. Indeed, although museums and galleries should be considered to be protected and controlled sites, objects on exhibit may nevertheless undergo colour changes to a greater or lesser extent. Numerous studies on this problem are reported in the literature. However, although it is well known, the problem of colour alterations induced by light exposure in artistic objects remains partly unsolved [10-12].

The ERA Project started from a previous long-term study carried out on the painting 'Predella della Trinità' by Luca Signorelli (1445-1523), on display in the Uffizi Gallery in Florence. This artwork was monitored over a period of 66 months (May 1990 - November 1995), by means of non-invasive measurements based on the Fibre-Optics Reflectance Spectroscopy (FORS) technique [13].

Different points selected on the painting surface were periodically measured in-situ, and even minimal colour changes occurring in time but not appreciable to the naked eye were revealed. At the end of the experiment, it was found that non negligible variations in colour had occurred in many points of the painting, although it was exhibited in a controlled environment. This case study showed that the standard systems for environmental monitoring might be insufficient for guaranteeing the appropriate conservation conditions for preventing damage in some objects. Based on these findings, a systematic study was carried out of the changes in the chemical and physical properties of traditional paint media responsible for the chromatic alterations observed. To that end, a series of 'mock paintings', that is, panels that included a set of painted strips prepared from materials of artistic interest were prepared, and exposed close to selected artworks in museums (Figure 1). The painted strips were realised in accordance with traditional artists' recipes, using different pigments and binding media. The following pigments were selected: indigo, azurite and smalt (blue pigments), turmeric (curcumin), lead (II) chromate and lead antimoniate (yellow pigments), vermilion, alizarin, cinnabar (red pigments), Sienna earth (brown pigment) and lead white. The strips were exposed upon different ageing conditions, both in climate chamber and in-field, by exposure in different museum sites. In the artificial ageing tests, the pigments alterations induced under controlled conditions by the various parameters, such as light, temperature, relative humidity and several pollutants ( $\mathrm{NOx}$ and $\left.\mathrm{SO}_{2}\right)$, could be evaluated. The changes occurred after exposure were measured by means of different techniques (non-invasive reflectance spectroscopy, thermoanalytical techniques, and microscale analytical mass spectrometry for molecular structure analysis). Moreover, the variations obtained in the panels exposed 
under real conditions in the different museums sites were evaluated, and a comparison with the results from laboratory tests made it possible to assess the impact of the micro-environment. Obviously, the in-field experiments also included a control of environmental conditions ( $\mathrm{T}, \mathrm{RH} \%$, light); therefore, the changes registered on samples exposed in-field could be related to the specific environmental conditions.

In this way, the mock-painting panels were used as indicators of the stress environmental conditions for the paintings on exhibit, and, in particular, for studying the cumulative effects due to complex environmental conditions. The overall experimentation (in-field and in the laboratory) pointed out that some pigments were prone to environmental agents, showing a variation in their original appearance, whereas other pigments remained unchanged [9]. Moreover, it could be observed that these effects were enhanced by the cooperative action of different agents. The comparison between the laboratory tests and the in field exposures showed that a given colour variation could be caused by various environmental parameters (light, an increase in temperature, the presence of $\mathrm{NOx} / \mathrm{SO}_{2}$ ). Consequently, the final alteration registered in situ could be attributed to a cumulative action of different factors. A more detailed analysis of the spectral data, which was based on multivariate analysis (PCA), made it possible to conclude that light was the main factor affecting the pigments of the panels exposed in the museums. Many other results (not reported here) corroborated the hypothesis that changes observed in the pigment tested could be explained only in terms of cumulative environmental impact, because light by itself could not account for the overall changes observed.

Figure 1. a) The mock paintings panel exposed in the Pollaiolo Room at the Uffizi Gallery Florence. b) The panel exposed together with conventional instruments for monitoring environmental parameters (temperature, $\mathrm{RH} \%$, visible and UV light). c) Detail of the panel.

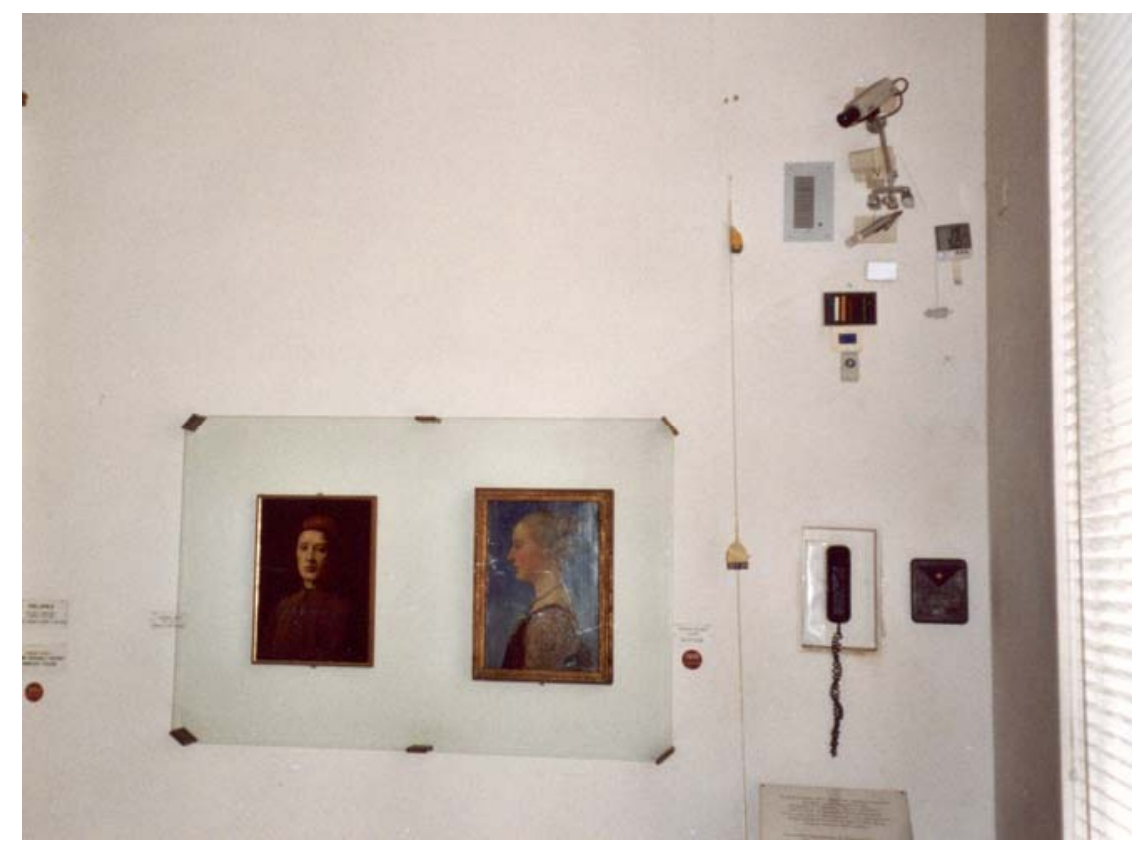

(a) 
Figure 1. Cont.

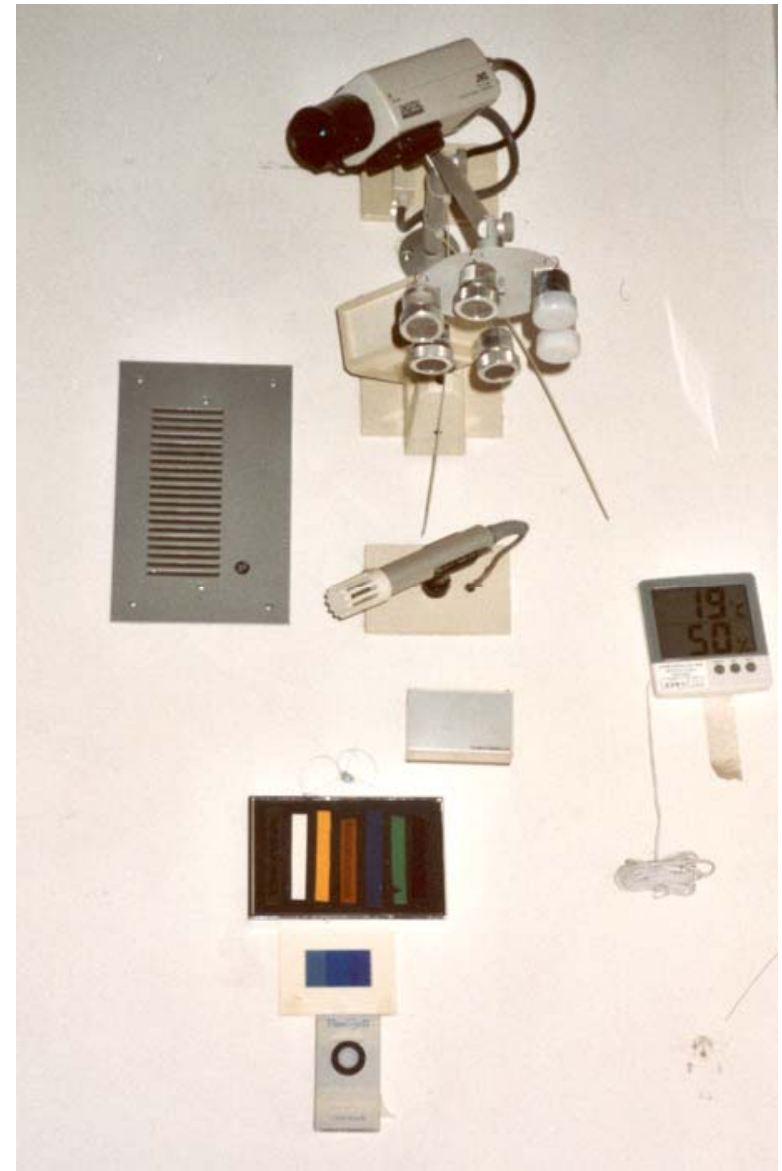

(b)

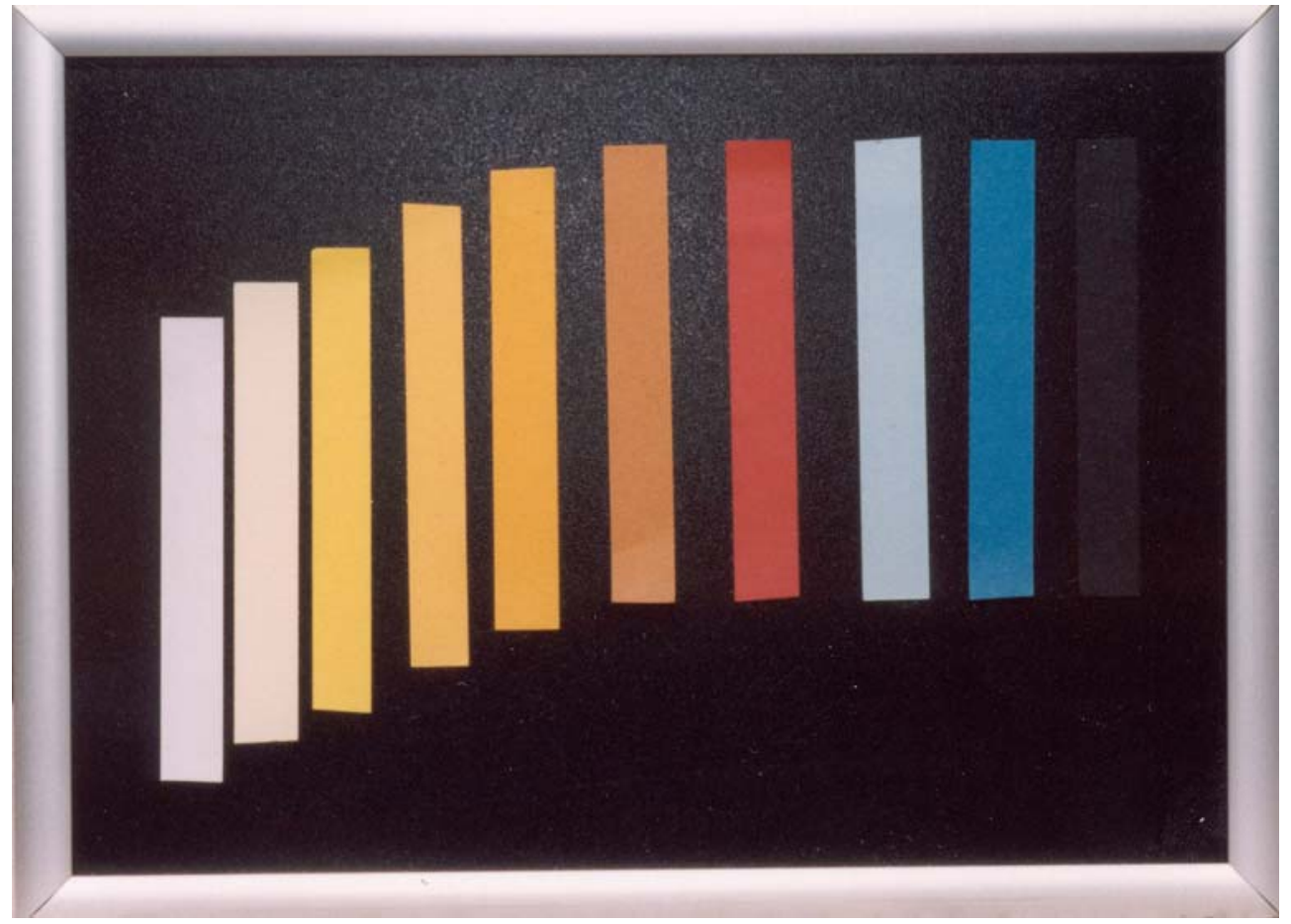

(c)

To summarize, an essential outcome of the ERA Project was to show that the concept of a mock dosimeter makes sense as a complementary tool for monitoring the environmental impact on complex 
objects (such as artefacts), since a separate control of temperature, light, and pollution is not sufficient to prevent risks of damage, owing to the cooperative effect of all these agents.

Subsequently, this work was further extended thanks to another research project (MIMIC: Microclimate Indoor Monitoring in Cultural Heritage Preservation) [14], in which similar test panels containing pigmented strips were adopted in order to evaluate the microclimate in a museum environment. In this case, the focus was on the action of atmospheric pollutants, and the effects of agents such as $\mathrm{NO}_{2} / \mathrm{NOx}, \mathrm{SO}_{2}$, ozone, $\mathrm{HNO}_{2}$ and $\mathrm{HNO}_{3}$ were evaluated, by means of both artificial ageing tests and in-field exposure. Different northern and southern European locations were selected for the exposures, so as to cover a variety of real conditions. A simultaneous control of environmental conditions was also performed.

In addition to the mock-painting dosimeters, other non-conventional tools were proposed within the framework of the MIMIC project in order to study the microclimate impact on artefacts. Sensors based on piezoelectric quartz crystals (PQC) and coated with materials of artistic interest (egg tempera, resin mastic varnishes) were prepared and tested under different exposure conditions. The working principle of a PQC sensor is that its oscillation frequency depends on the mass of coatings, and this frequency is shifted after a modification in the film due to ageing and to interaction with pollutants [15].

All the sensors presented above are characterised by the fact that they are based on materials (pigments, bindings) which are present in the composition of artworks and are the most exposed to environmental attack. The idea was to reproduce, although in a simplified way, the same damage process as the one observed in the object and then to identify its causes. The main drawback of this approach is that mock paintings are expected to show some evidence of deterioration only after prolonged exposures (many months) in field, or alternatively, under accelerating ageing tests in laboratory, that can not reproduce exactly actual conditions. In this sense, having a reaction time similar to that one of the artworks, these sensors are helpful to gain a deeper insight on causes of deterioration phenomena, but they can not be used to alert before the damage is occurred.

The next section describes a different concept of sensor. It is based on the use of sacrificial materials that react more quickly and give warning of risk situations, rather than simulating behaviour observed in the object.

\subsubsection{An early-warning system for monitoring light sensitive artworks: the LightCheck® System}

Another example of colorimetric sensor developed for the control of museum environments is the LightCheck ${ }^{\circledR}$ (LC) system. This was the final outcome of the EC-funded project "LiDo: A Light Dosimeter for Monitoring Cultural Heritage: Development, Testing and Transfer to market”, which was aimed at delivering a new tool for monitoring light and preventing damage to photosensitive objects in museums [16].

As already mentioned, exposure to light (both natural and artificial) is among the main causes of the fading, discoloration and brittleness of many historic and artistic materials. Depending on the type of artwork and the materials that constitute it, different lighting conditions are recommended according to guidelines in order to guarantee both the enjoyment and the safeguarding of the objects. Unfortunately, because many materials are extremely sensitive to light (such as ancient paper, organic materials, watercolours, etc.), the recommended light levels are very low (e.g. $50 \mathrm{~lx}$ for the most sensitive materials) [3]. Therefore, the average lighting conditions in a museum room does not always fulfil 
these recommendations. The goal of the LiDo Project was to deliver a light-dosimeter for the most sensitive objects, which still suffer from a lack of specific tools for preventing photo-induced deterioration. In fact, although many different types of instrumentation (luxmeters, radiometers and data loggers) are available for lighting control, these pieces of equipment require trained staff and cumbersome procedures in order to guarantee a constant and large-scale monitoring, and many situations remain uncovered by controls.

LC was designed as a passive sensor tuned to respond to light much quicker than the artworks, so as to provide a clear indication of possible inadequate lighting conditions before the objects are actually damaged. The indicator was thus conceived as an alert system for singling out risks of excessive light exposure. The latter is an example of an Early Warning System (EWS), which has gained more and more importance since the concept of preventive conservation has been established in museum management to protect the cultural heritage [17-18].

Schematically, LC consists of a photosensitive dye/polymer coating applied to an inert substrate. The photosensitive layer undergoes a progressive variation in colour as the luminous exposure increases, and its response to light is cumulative. The dosimeter, which is exposed close to the object to be monitored, progressively changes its colour with a rapidity that depends on the environmental light levels.

LC includes two different dosimeters, LightCheck Sensitive (LCS) and LightCheck Ultra (LCU), with complementary operational ranges suitable for monitoring different categories of objects. Specifically, LCS controls moderately sensitive objects (e.g. oil paintings, wooden artefacts, etc.), whereas LCU is tailored to extremely sensitive objects (watercolours, photographs, etc.) [19]. Each LC is equipped with its own Colour Reference Card, which consists of five colour steps that are easily distinguishable to the naked eye and correspond to five stages of colour that are spanned by the dosimeter when it is exposed to light. For each colour step, a range of light doses is reported which indicates the corresponding exposure received by the dosimeter (Figure 2). The light dose is expressed in lux.hours (lx.h), in accordance with the conventions adopted in museum institutions. Hence, a simple periodic visual check of the colour attained by the dosimeter exposed close to the object would make it possible to establish whether the object has received the recommended light-dose, or, conversely, if it is at risk of over-exposures. Obviously, the quantitative indication of the light dose received is only an indicative datum, and should an anomalous situation be evidenced, further precision measurements by means of conventional instrumentation would be required in order to determine the lighting levels.

An aspect to be highlighted is that LC is tailored to monitor light-sensitive objects, thus it has been calibrated for lighting conditions typically adopted in museum environments. Thus, the reliability of the response can fails if the dosimeter is used under lighting conditions that are not envisaged for a museum context, such as inadequate light sources (e.g with intensities higher than $500 \mathrm{~lx}$ ), or direct sunlight, etc..

To summarize, LC cannot be used as a substitute for a conventional luxmeter, but instead represents a tool for a first-level lighting control. LC fulfils many of the requirements needed for use in a museum environment, because it is low-cost, disposable, aesthetically acceptable, and completely user-friendly. 
Figure 2. An example of the use of a colour reference scale for the LightCheck® system (LCU). After exposure close to the artefact, the colour of the dosimeter is visually compared with a colour reference scale that contains five labelled colour steps and indications of the corresponding light-doses. (Image reproduced with permission of the Trustees of the V\&A Museum, London. Photo by Maja Kardum).

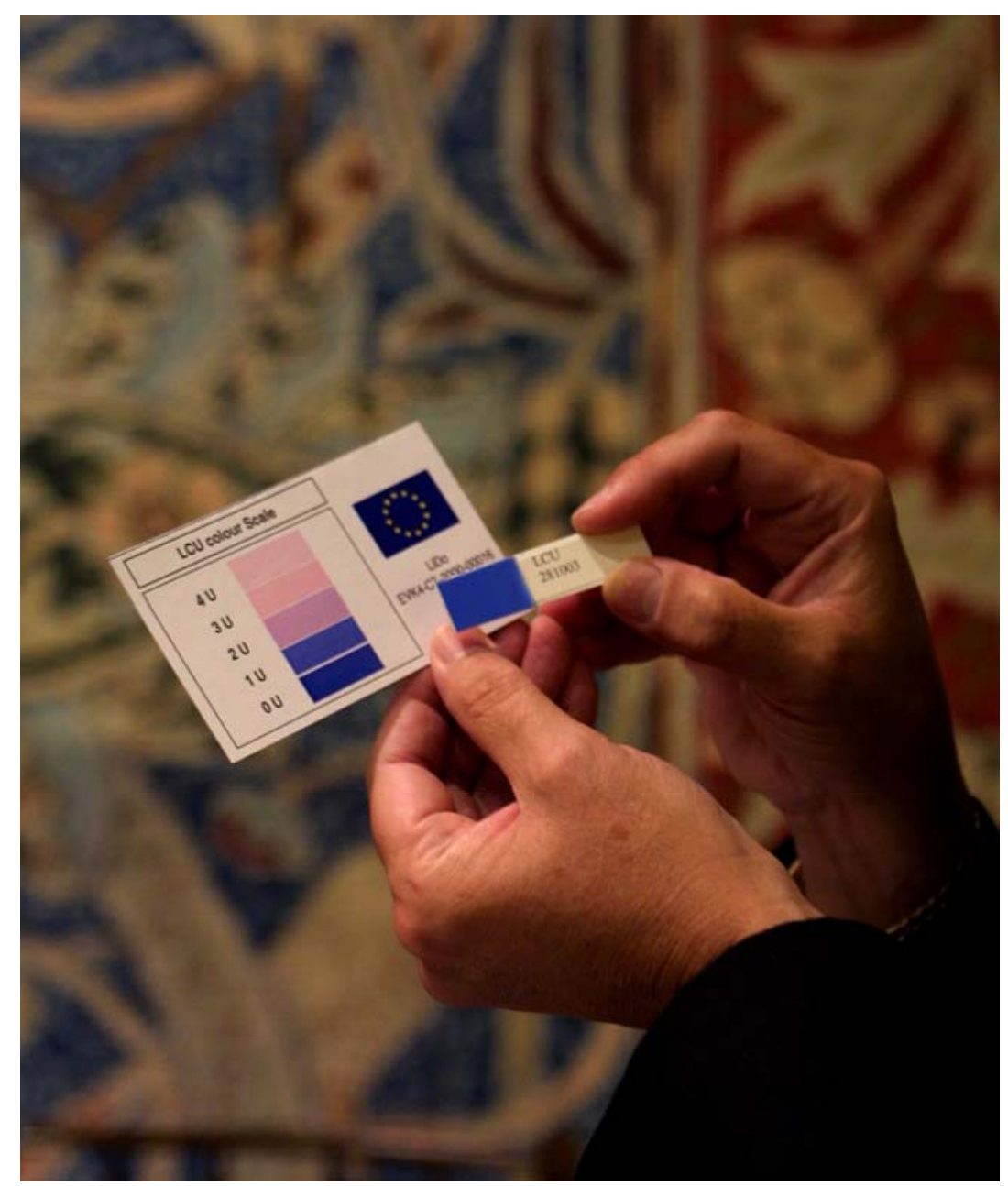

A precursor of LC is the Blue Wool Standard (BWS), which also deserves mention in the present review because of its still widespread use in the field of the cultural heritage and of conservation science [2, 10-11,20-22]. BWS, which was borrowed from the textile industry, consists of a series of 8 fabric-based wool cloths dyed with blue dyes of increasing light fastness, according to the international classification (ISO-categories) of light stability for modern textile colours. In the BWS scale, the most fugitive is n.1 (BWS1), and the most stable level is n.8. In many cases, the BWS is used to evaluate the light-fastness of artistic materials by means of a visual comparison after a given exposure; alternatively, it is employed to test the average lighting conditions by evaluating its decolouration after exposure in a given environment. Nevertheless, it has been proven that BWS is not suitable for use as an early warning tool, since even the most fugitive level (BWS1) is not sensitive enough to respond in the typical lighting conditions recommended for photosensitive objects (with an average illuminance intensity of about $50 \mathrm{~lx}$ ). The LC was in fact designed to make up for BWS's lack of sensitivity, and was tuned to clearly respond to light-doses of between 0 and $500 \mathrm{klx}$.h, i.e. an interval of exposures not 
covered by BWS1. More precisely, LCU is suitable for responding over the 0-100 klx.h light-doses range, whereas the LCS covers the 100-400 klx.h range [19].

\subsection{Monitoring tools for atmospheric pollutants}

Air quality is another important aspect that needs monitoring in museum environments in order to ensure care and protection of the objects on display.

Indoor atmospheric pollutants may be responsible for various chemical reactions with materials (e.g. pigments, binders, etc.) constituting artefacts, thus causing their irreversible deterioration. Moreover, dust and soot deposits can lead to the soiling of surfaces, and can in turn be a medium for further chemical reactions with other atmospheric pollutants. Possible sources of indoor pollution in museums rooms are the presence of the public, the flow of polluted air from windows, and the use of inadequate cleaning products [23]. In particular, when defining indoor air quality in museums, the focus is on the following components: $\mathrm{SO}_{2}, \mathrm{NO}_{\mathrm{X}}, \mathrm{O}_{3}$ and VOC. As for the materials, the ones most exposed to chemical reactions are organic ones - such as textiles, paper, wood, leather, etc. - since these may undergo embrittlement, cracks, and fading due to chemical attack by atmospheric pollutants. Hence, the control of indoor air quality in combination with microclimate control ( $\mathrm{T}$ and $\mathrm{RH} \%$ ), plays a fundamental role in ensuring correct conservation conditions.

Here as follows two different concepts of sensors tailored to monitor effects of indoor pollution in museums will be illustrated: "cumulative sensors", which are dosimeter-like and respond to the atmospheric agent(s) with an additive reaction, and "reversible sensors", which can be re-used a certain number of times since they recover their original status when initial conditions are restored.

\subsubsection{Cumulative sensors}

Various innovative approaches have recently been proposed for the control of pollutants in museums [24]. Among these, a meaningful example is the "EWO" (Early Warning Organic) dosimeter, developed within the EC MASTER Project, a program focused on the problem of chemical deterioration of organic materials in artworks [25-27].

EWOs are smart passive sensors designed to sense the presence of $\mathrm{SO}_{2}, \mathrm{O}_{3}$ and $\mathrm{NO}_{2}$. These dosimeters are cumulative, aesthetically non-invasive and, analogously to the previous example, were devised in order to serve as an early warning system. They are based on a polymeric dyed film applied over a glass substrate. The active layer changes its absorption spectrum after interaction with specific pollutants. An optical measurement of the absorption spectrum of the dosimeter before and after exposure makes it possible to estimate the concentration of the pollutant. Different types of EWO have been developed that are suitable for responding to pollutants, either selectively $\left(\mathrm{SO}_{2}, \mathrm{O}_{3}\right.$ and $\left.\mathrm{NO}_{2}\right)$ or to the cumulative action (generic impact sensor) of $\mathrm{NO}_{2}, \mathrm{O}_{3}$, temperature and UV-light.

As already mentioned, the EWO dosimeters were developed specifically for the prevention of damage in organic materials. Nevertheless, it is known that atmospheric pollutants can also attack different categories of materials, such as metallic artworks. In this case, the typical phenomenon to be prevented is corrosion, which can be induced by many cooperating parameters, such as temperature, relative humidity and pollutant gases. Once again, this deterioration phenomenon is rather complex, and is difficult to monitor and prevent [28]. Metal sensors, i.e. coupons made from the same material to be monitored, are an appropriate tool for assessing corrosion risks due to environmental impact [29- 
30]. Usually, a mass (gain or loss) measurement is made on the metallic coupons after their exposure, in order to assess the aggressiveness of a given environment.

Other approaches for quantifying corrosion are based on quartz crystal microbalances, in which the changes in the resonance frequency of a piezoelectric crystal with a metal coating are measured after a given exposure time. These microbalances are quite sensitive in detecting the phenomenon; however, they are sophisticated, mechanically vulnerable devices that are not available at a low cost. Therefore, alternative solutions have been sought.

Very recently, within the framework of the EC CORRLOG Project, an interesting prototype based on the electric resistance technique was proposed [31-33]. This sensor consists of a thin metallic track of the material of interest (e.g. zinc, iron, copper and nickel), deposited on a non-conductive substrate (Figure 3). The electrical resistance of the track (i.e. the measuring element) increases as its cross section diminishes, due to corrosion. The sensor includes two elements: one is exposed to the environment, and the other is shielded and used as reference. The resistance changes are measured as differences between the two elements, by means of an electronic unit. The thickness of the metallic track defines the sensitivity and the service life of the sensor. The lower the thickness, the greater the sensitivity. This feature makes it possible to tune the sensitivity according to the application, and in particular to provide high-precision units suitable for indoor applications. Furthermore, the corrosion of outdoor metallic artefacts (e.g. statues) still represents an important conservation problem in the cultural heritage field. Although they are only in their preliminary stage, however, these sensors have a strong potential also for outdoor applications.

Figure 3. The CORRLOG sensor for monitoring corrosion in metallic artefacts. (Photo: courtesy of Tomas Prosek).

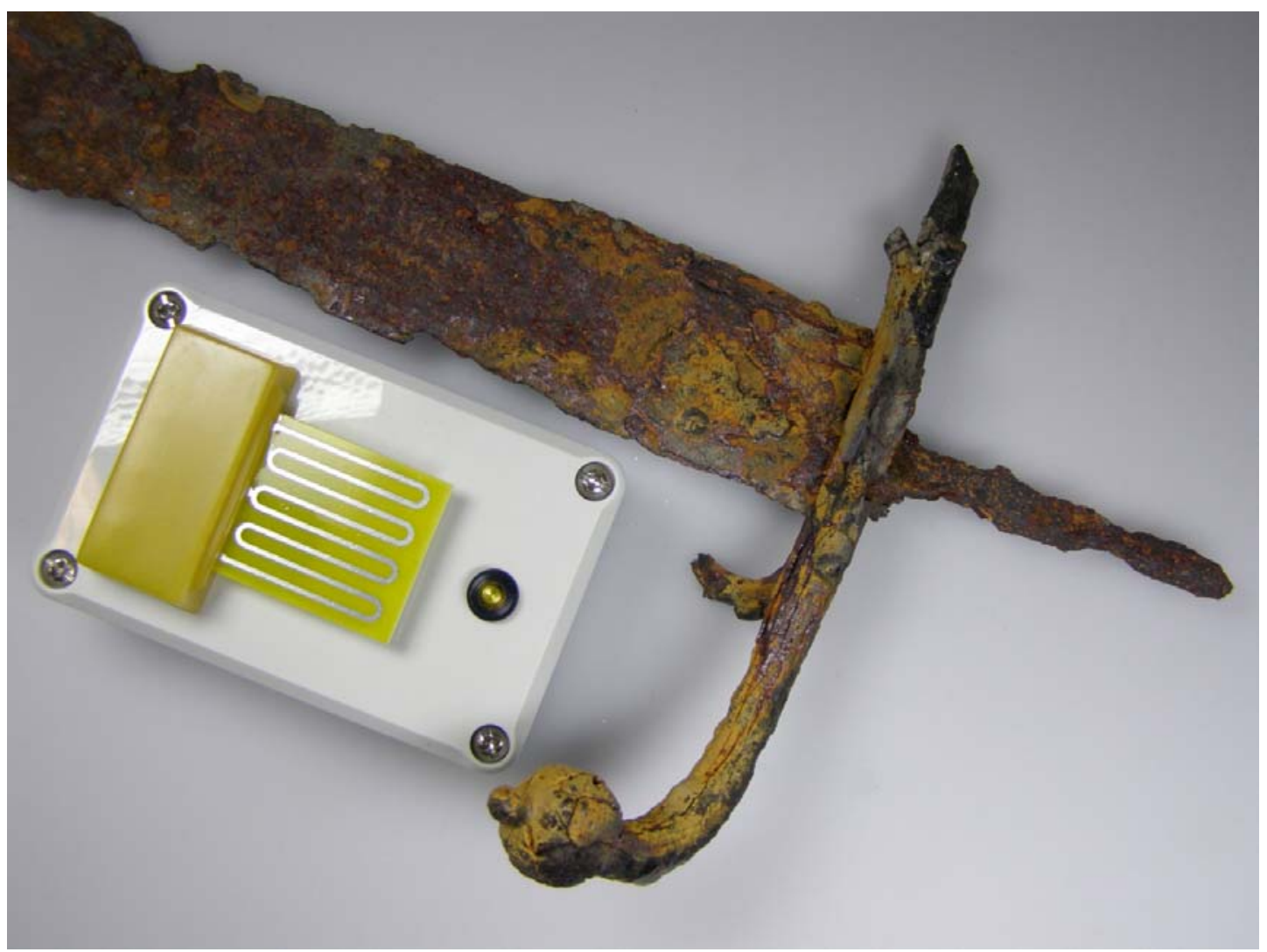




\subsubsection{Sol-gel based reversible sensors}

The sol-gel technique is a very advanced technology that offers several advantages as far as the preparation of thin films with different functional properties is concerned. Therefore, this technology appears highly promising for designing the type of versatile and sensitive sensors that are needed in the conservation field, where different agents may be of interest, depending on the typology of objects to be surveyed. Sol-gel matrices make it possible to immobilise several kinds of chromophores. These can interact with different external chemical species, such as solvents, gaseous pollutants, moisture, etc., thus indicating their presence in the environment.

Very recently, two optical sensors based on sol-gel technology have been proposed for the simultaneous monitoring of relative humidity and environmental acidity in museum environment [34] . Using the same sol-gel matrix, two different organic dyes - i.e. crystal violet (CV) and chlorophenol red (CR) - were encapsulated in it, in order to obtain two coatings with different sensing features. Laboratory tests showed that the CV-coating was sensitive to both relative humidity (in the 20-90\% range) and acid-base equilibria $\left(\mathrm{H}_{3} \mathrm{O}^{+}\right.$and $\mathrm{OH}^{-}$species), by displaying a colour change from green to deep blue after exposure. Conversely, the CR-coating was stable against changes in relative humidity, whereas it was found to be sensitive to $\mathrm{SO}_{2}(10-50 \mathrm{ppm}$ range), i.e. it reacted in the presence of pollutants capable of changing the environmental $\mathrm{pH}$, by changing its colour from violet to orange.

Two very important features of these sensors are their rapid reaction time (about 10 minutes of exposure) and their reversibility, since they recover their original appearance when starting conditions are restored. Therefore, when placed together close to the artwork, the CV and CR sensors would make it possible to monitor the conditions of relative humidity and environmental acidity, and could be used to characterise the environment from the point of view of the cooperative effects between environmental humidity and acidity. Indeed, with the presence of acid pollutants, both sensors will change colour: namely that of the $\mathrm{CV}$ will range from green to blue, and that of the $\mathrm{CR}$, from violet to orange. On the other hand, if there is a risk of deterioration simply due to high levels of relative humidity, but in the absence of acid pollutants, only the CV sensor will react, by changing colour after a few minutes, whereas the CR one will remain unchanged. This way, it is possible to use the pair of sensors to obtain a rapid and easy indication of the correctness of the conservation conditions of objects (e. g. in showcases).

These sensors are still at the stage of prototypes and therefore cannot yet be considered competitive with the standard instrumentation available for monitoring environmental relative humidity. Nevertheless they are interesting examples of a very innovative concept of reversible sensor, which is of great interest for applications in museums context, where tools for quick and repeated checks are highly helpful for ensuring care of artefacts.

\section{Optical fibres for the cultural heritage}

In recent decades, optical fibre technologies have gained more and more diffusion in the fields of the cultural heritage and conservation, thanks to their great versatility and potentiality for customised applications. In fact, optical fibre sensors have proved to be suitable for responding to specific sensing problems, especially for non-stop monitoring in real time, the implementation of automated nondestructive measurements in-situ, and the control of parameters that can either affect the conservation 
or influence user perception (e.g. colour). Furthermore, optical fibres have been found to be particularly suitable for the museum environment, since they are made of transparent and dielectric materials [35]. Transparency fulfils many aesthetic requirements, whereas dielectricity provides intrinsic safety against sparkle and spikes. Lastly, the most novel applications of fibre optics involve the implementation of wide-ranging networks of sensors for the simultaneous monitoring of different rooms or sites, thus ensuring the widespread control of extensive areas.

The museum community started using fibre-optics technologies for illumination applications. Indeed, fibre-optics-based systems make it possible to easily filter out UV and IR components of the radiation, thus providing a safer illumination for sensitive objects [36]. By means of optical fibres, light can be guided remotely from the source, so that even barely reachable zones can be suitably illuminated. In particular, optical fibre-based systems are employed for lighting objects in showcases, in which they permit a correct illumination of the artwork while avoiding the problem of internal heating.

In addition to these well-established applications in lighting environments, fibre-optics technology offers great potentiality in the field of sensors and monitoring devices for the care of artefacts. As far as the diagnostics and restoration of artworks are concerned, optical fibres are widely used for implementing the applications of several optical techniques (FORS, Raman, fluorescence, etc.) employed for the characterisation and identification of materials. Indeed, thanks to the use of optical fibres, repeated and precise non-invasive in-situ measurements can be carried out without the need of displacing the artwork, and/or on specimens with complex shapes [6, 37-40].

From the point of view of environmental monitoring, there are many examples of compact opticalfibre sensors and devices that have been specifically designed for controlling museum environments and customized in order to respond to specific conservation problems.

As general comment it has to be pointed out that optical-fiber systems are more complex and sophisticated with respect to dosimeters and sensors based on sacrificial materials. Thus, their main limitation is that they may require trained staff to be used, and usually they are not low cost systems.

The present section is devoted to illustrating selected optical-fibres-based systems designed for the cultural heritage. Given the large number of optical fibre based devices, this section cannot be exhaustive, but rather intends to present some meaningful examples that could highlight the innovation potential of the fibre optics technology in the field of cultural heritage.

\subsection{An optical fibre sensor for monitoring varnished layers}

In the conservation field, in addition to routine environmental controls, it is often important to provide tools for responding to very specific conservative problems that require a customized technological solution. In this paragraph, a prototype sensor designed for the in-situ monitoring of thermal excursions on paintings is illustrated. This device is based on a varnished optical fibre, and is especially applicable for controlling varnished paintings. This device could be particularly helpful in preventing risk conditions that can arise when illuminating paintings with the use of lamps, as happens during television shots [41].

As is well known, transparent varnishes have been always applied by artists as protective layers to painted surfaces. Indeed, beside protecting the pictorial film, varnish enhances colours, thus 
"improving” the final visual effect. This is because the layer of varnish creates a microscopically smoother surface, and provides a refractive-index matching medium between the air and the pigments [42]. Hence, the incident light penetrates the paint layer more thoroughly, and so it appears glossier. Moreover, owing to multi-reflection, the scattered white light is reduced, thus producing more saturated colours.

On the other hand, it is well-known that varnishes themselves are prone to deterioration, since they can change their physical characteristics after prolonged exposure to light and other environmental parameters ( $\mathrm{T}$, RH, etc.). Varnish ageing is, in fact, a well-recognized conservation problem, and is responsible for many damage phenomena, such as chromatic changes, cracks, etc..

In the sensor presented here, once again, as for the colorimetric sensors (Par.2 1), the properties of the material to be surveyed have been exploited as a sensing principle. More specifically, a varnish coating over a plastic-cladding silica core (PCS) optical fibre was applied by stripping off a short length of the cladding and replacing it with a layer of varnish (Figure 4). The working principle of the sensor is very simple. A light signal emitted by a LED source is sent simultaneously to both a reference non-treated fibre and to the varnished fibre. The sensor output is the ratio between the signal of the varnished fibre and that of the reference fibre, and provides information as to the extent of the ageing of the varnish coating. Indeed, since the light intensity guided by the optical fibre depends on the refractive index of the varnished fibre section, any variation in temperature affecting the varnish refractive index results in a light modulation.

Figure 4. Scheme of the varnished optical fibre used as a probe-head in the sensor for monitoring painted surfaces.

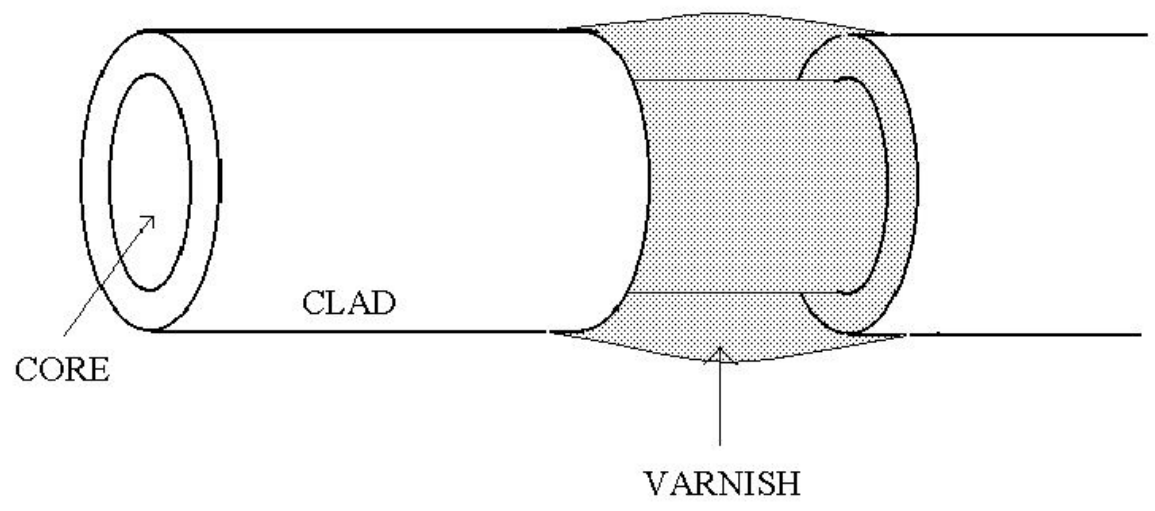

In this experiment, three kinds of varnishes commonly used in painting restoration were tested, namely: dammar resin, amber in linseed oil and gum mastic. A calibration of the response sensor was attained by performing temperature cycles in the $20-65^{\circ} \mathrm{C}$ range. The thermal sensitivity and the reversibility of the changes in the varnishes properties were tested. All three varnishes types exhibited a temperature sensitivity to some extent. In particular, the thermal behaviour of the refractive index was found to be fully reversible for gum mastic, slightly sensitive and poorly reversible for amber, and irreversible for mastic. As a result, gum mastic was identified as being the most suitable material for implementing a temperature sensor. 
Thus, by permanently embedding the fibre-optic sensor in the painting (in a corner, for example) together with the picture varnish, it would be possible to monitor the temperature at the surface of the painting continuously.

A drawback of this system is that it needs a complex preliminary procedure to be applied to the painting. In this sense it can not be considered suitable for widespread and routine controls, and it is intended only for very specific cases.

\subsection{Optical fibres for monitoring light}

The examples described here as follows are prototypes of fibre-optic sensors developed in order to cope with the problem of lighting control. As already mentioned, a correct illumination in museum rooms is a basic principle of preventive conservation, since photo-induced chemical reactions are the cause of many degradation phenomena in artworks.

The first example is an extrinsic, intensity-modulated fibre-optic sensor in which the sensitive element is a photochromic material consisting of fulgides immobilized on a polymeric matrix The photochromic transducer reacts to radiation in the UV-VIS spectral range, since it is coloured by UVlighting and bleached by VIS-lighting. By measuring the temporal variations in the absorbance of the photochromic transducer, it is possible to deduce the fraction of UV and VIS levels [43]. The measurement is precise, and the sensor is suitable for monitoring individual objects on display. Aesthetically speaking, the system is non-invasive. Since it is assembled with low-cost, commercially available components, many units can be provided at affordable prices to museum-type institutions.

Although very innovative and interesting for its working principle, this system is still at the stage of prototype and is not competitive with conventional luxmeters and dataloggers for measurement of UV and visible light.

The second case involves assessing the average environmental lighting conditions in museums rooms, and consists of a fibre-optics-based instrumentation for the continuous monitoring of light. This device (shown in Figure 5) is based on the real-time measurement of the colour variations in test materials (e.g. BWS) induced by environmental light. The samples of BWS (or other photosensitive materials) are mounted on a rotating holder, and remain exposed to the environmental lighting for a given time of exposure (typically, several months). The change of colour in the samples is monitored periodically, thanks to the automated measurement of their reflectance spectrum. By means of a periodic rotation of the holder, the samples are moved in front of a fibre optic probe that is connected to a miniaturized spectrophotometer and housed in a casing. Reflectance measurements are carried out automatically at the desired rate, and the spectral variations, which are due to the exposure of samples to the environmental light, are monitored. A reference sample is always kept in the dark, so that the colour difference between the exposed samples and the reference can be calculated at any given time. Dedicated software with a customized interface makes it possible to follow the colour change over a long period, and to give warning in the case of anomalous situations.

This instrumentation was first designed to carry out tests of "equivalent light dosimetry", i.e. in order to gain deeper insight into the cooperative effects of light and the other, uncontrolled environmental factors in fading materials. Indeed, as previously mentioned, chromatic damage in artworks is due not only to overly intense light, but also to the combined action between light and 
pollutants, thermo-hygrometric fluctuation, etc. Based on this, the concept of "equivalent light-dose" was introduced, in order to quantify the hazardous nature of the overall environment in regard to a specific artwork [44]. This instrumentation was tested in the field during different campaigns exposures. In particular, an experiment carried out at the Uffizi Gallery (Florence) showed that photoinduced colour changes can be enhanced by the overall microenvironment. It also showed that the concept of equivalent light dosimetry makes sense for assessing the overall impact of light and other environmental parameters [2]. However, it has to be pointed out that the indication provided in terms of "equivalent light dose" is always referred to the response of the material test, for example the BWS, used for exposures. Hence, it has to be considered as an indication about the presence of cooperative effects between light and other agents, and about the entity of their impact on the material test. Conversely, the equivalent light dose can not be assumed as a quantitative indication on the impact on objects exposed in the same environment, since different materials are expected to react differently.

Figure 5. (a) The optical-fiber device for monitoring lighting conditions in museums: the spectral features of exposed samples are visualized in real time on the PC. (b) View of the optical fiber probe connected to the miniaturized spectrophotometer within the case.

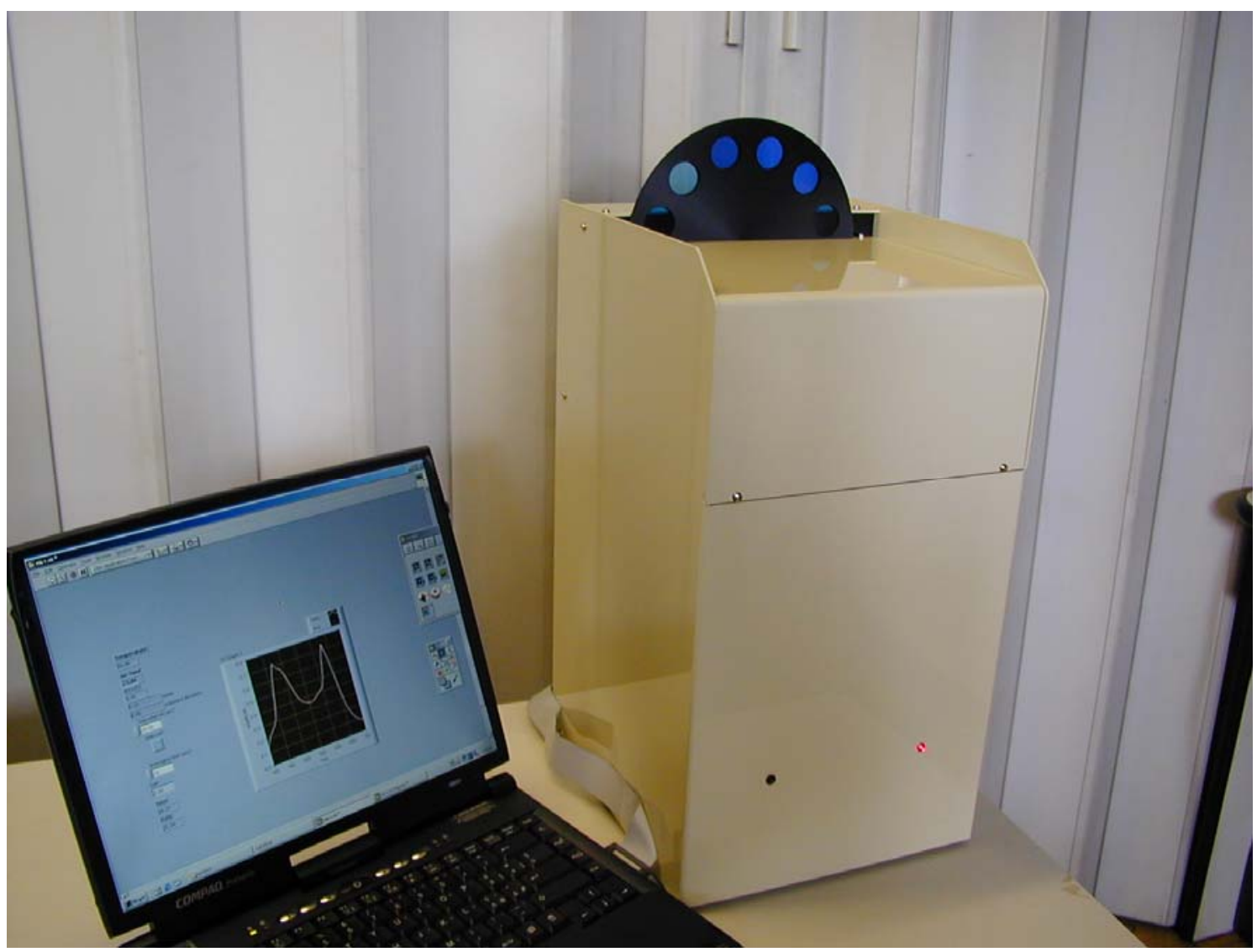

(a) 
Figure 5. Cont.

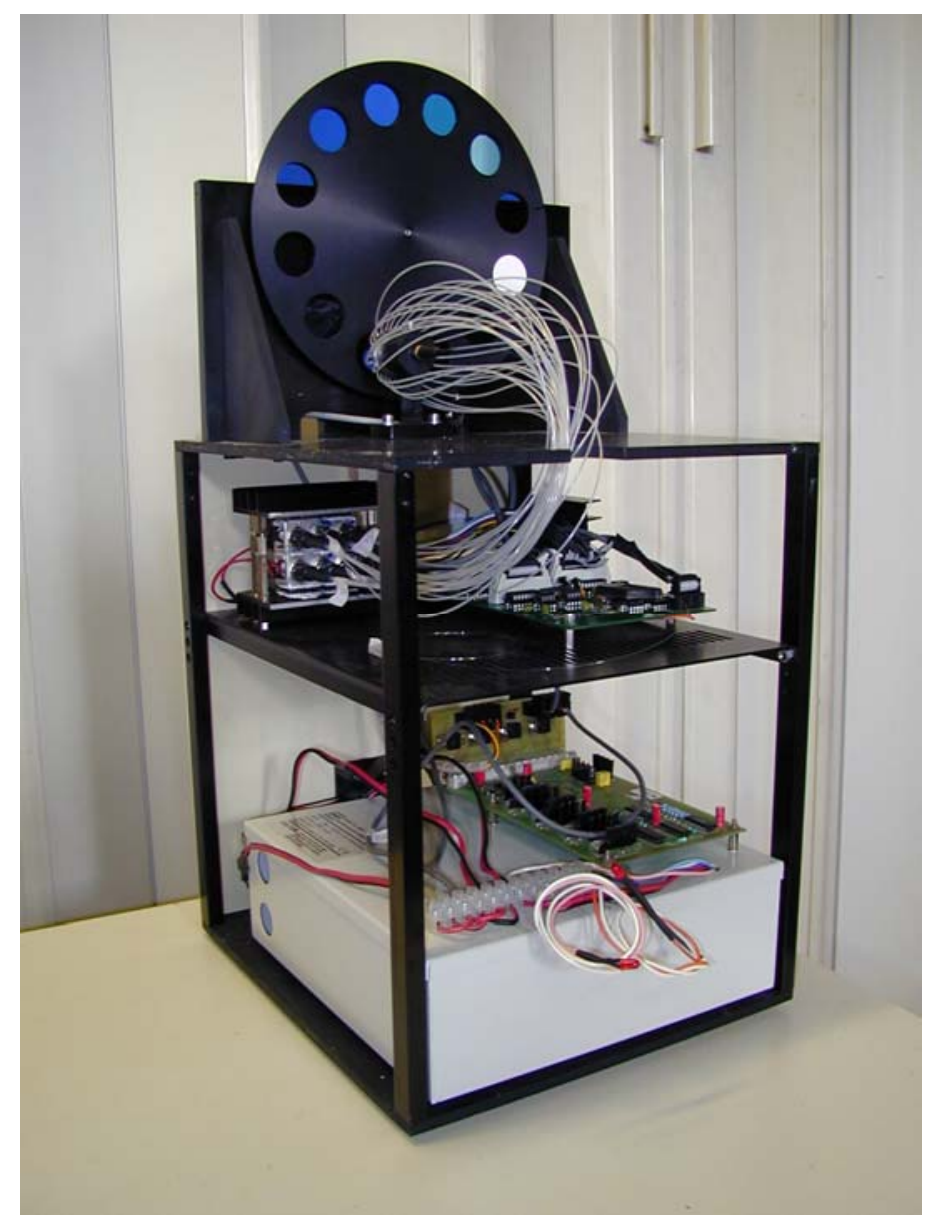

(b)

\subsection{A Bragg grating sensor for diagnostics of wooden artworks}

The example presented here is a sensor based on high-precision optical techniques and intended for the restoration and conservation of wooden artworks. It is well known that relative humidity and temperature fluctuations can deform wooden objects (including support panels, artefacts, etc.) and cause their mechanical deterioration. Methods currently adopted for evaluating differential movements and micro-cracks in wooden artworks are based on the measurement of displacements of reference points fixed on the panel [45-46]. In this type of measurement, high precision and reproducibility are crucial in order to obtain reliable information; therefore, optical methods appear particularly promising.

This sensor, designed to monitor deformations in wooden artefacts, is based on the fibre Bragg grating (FBG) [47]. The FBG sensor is an intrinsic, wavelength-modulated optical-fibre-based device, which consists of a periodic perturbation of the core refractive index of a UV-sensitive optical fibre. The radiation generated by a broad source is injected into the fibre, where it interacts with the Bragg grating and gives rise to a characteristic output. Indeed, due to the presence of the Bragg grating, only the Bragg wavelength (actually a very narrow range of wavelengths) can be back-reflected along the fibre without causing any perturbation, and this particular wavelength depends on the grating pitch and on the effective refractive index of the fibre. Any physical parameter that changes the fibre pitch and 
the fibre transmission characteristics may produce a shift of the wavelength. Based on this principle, it is possible to monitor elongations (strains) and temperature changes in the support to which the device is applied, since these both have the effect of modulating the Bragg wavelength.

By inscribing a number of gratings with different resonance wavelengths in the same fibre, it is possible to carry out a quasi-distributed measurement. This system offers the advantage of a very high resolution, very low invasivity, and the possibility of multiplexing for a quasi-distributed measurement configuration with a single optoelectronic unit. Its main limitation is the due to the fact that it is based on precision optical components, and therefore is not suitable for implementing widespread and lowcost monitoring plans.

\section{Summary}

In recent years, the concept of "preventive conservation” has become an undisputed basis for the protection of artwork collections and for the management of museum environments. Preventive conservation is a global approach that includes a series of rules and complementary solutions for minimizing and slowing down the deterioration of artworks, by controlling the environment of the collections. As both the number of museums and the number of artworks on display is on the increase, the exclusive concentration on the preservation of individual objects severely limits conservation care for the bulk of a collection. The idea is, therefore, to safeguard collections on the whole, by means of procedures that ensure high standards of storage and maintenance of their artworks.

Within this framework, innovative tools such as early-warning systems, passive sensors, dosimeters, and dedicated devices that can help in risk assessment and in the prevention of environmental damage are greatly in demand by conservators. These tools are required to complement in different ways the conventional methods for environmental monitoring. In some cases they are designed to detect effects which can not be measured by standard instrumentation, for example assessment and prevention of deterioration phenomena induced by synergistic action of many environmental factors. In other circumstances these devices are used as early warning systems, that is they are intended for preliminary screening, in order to alert about possible risk situations (e.g. inappropriate lighting conditions). Once a critical situation is identified, further controls by means of precision measurements are nevertheless required.

In any case, all these non-conventional sensors cannot be considered as substitutes of standard instrumentation, since they are capable of providing only semi-quantitative indications. Indeed, being typically based on sacrificial materials, or on a simulation working principle, these sensors can only simulate in a very simplified manner the phenomenon to be monitored. Nevertheless, they can turn out to be precious tools to interpret data provided by standard instrumentation, as well as to provide information that can not be inferred by separate measurements of all the parameters.

In addition to dosimeter-like sensors, more sophisticated systems based on fiber-optic technology represent an important class of devices for the museum environment. These tools are optimal for customized solutions to specific conservation problem. Nevertheless, due to the use of precision optical components have generally the limitation of costs and need of trained personnel. 
The examples presented here review some of the most meaningful results of excellent research projects that have successfully concluded with the production of innovative prototypes, and are now waiting hopefully for them to be circulated within the conservator community.

\section{References}

1. Brommelle, N.S. The Russel and Abney report on the action of light in water colours. Stud. Conservat. 1964, 9, 140-152.

2. Bacci, M.; Cucci, C.; Mencaglia, A. A.; Mignani A. G.; Porcinai, S. Calibration and use of photosensitive materials for light monitoring in museum: the Blue Wool Standard 1 as a case study. Stud. Conservat. 2004, 49, 85-98.

3. Tétreault, J. Airborne Pollutants in Museums, Galleries and Archives: Risk Assessment, Control Strategies and Preservation Management”. Canadian Conservation Institute: Ottawa, 2003; p.168.

4. Bacci, M.; Baldini, F.; Carlà, R.; Linari, R. A Color Analysis of the Brancacci Chapel Frescoes. Appl. Spectrosc. 1991, 45, 26-31.

5. Bullock, L. Reflectance spectrophotometry for measurements of colour change. Nat. Gall. Tech. Bull. 1978, 2, 48-55.

6. Bacci, M.; Casini, A.; Cucci, C.; Picollo, M.; Radicati, B.; Vervat, M. Non-invasive spectroscopic measurements on the Il ritratto della figliastra by Giovanni Fattori: identification of pigments and colourimetric analysis. J. Cult. Herit. 2003, 4, 329-336.

7. $\quad$ EC funded project. Contract n. EV5V-CT-94-0548.

8. Odlyha, M.; Boon, J. J.; van den Brink, O.; Bacci. M. Environmental research for art conservation (ERA). J. Therm. Anal. Calorim. 1997, 49, 1571-1584.

9. Bacci, M.; Picollo, M.; Porcinai S.; Radicati, B. Tempera-painted dosimeters for environmental indoor monitoring: a spectroscopic and chemometric approach. Environ. Sci. Technol. 2000, 34 (13), $2859-2865$.

10. Thomson, G. The museum environment, Second Edition. Butterworth-Heinemann - Ed. Elsevier: Oxford, 1994.

11. Thomson, G. A New Look at Colour Rendering, Level of Illumination, and Protection from Ultraviolet Radiation in Museum Lighting. Stud. Conservat. 1961, 6, 49-70.

12. Padfield, T.; Landi S. The Light-Fastness of the Natural Dyes. Stud.Conservat. 1966, 11, 181196.

13. Bacci, M.; Picollo, M.; Porcinai, S.; Radicati, B. Spectrophotometry and colour measurements. Techne 1997, 5, 28-33.

14. EC funded project. Contract n EVKV-CT-2000-00040.

15. Odlyha, M.; Theodorakopoulos, C.; Thicket, D.; Ryhl-Svendsen, M.; Slater J.M.; Campana, R. Dosimeters for indoor microclimate monitoring for cultural heritage. In: Museum Microclimates Proc. Conference Copenhagen 19-23 Nov. 2007; Padfield, T.; Borchersen, K., Eds.; National Museum of Denmark: Copenhague, 2007; pp. 73-79.

16. EC funded project Contract nº: EVK4-CT-2000-00016, http://www.lido.fhg.de. 
17. Dahlin, E. Preventive conservation strategies for organic objects in museums, historic buildings and archives. In General report of the $5^{\text {th }}$ EC Conference of Cultural heritage Research, Cracow (Poland) 12-15 May 2002. http://heritage.xtd.pl/pdf/full_dahlin.pdf .

18. Cassar, M. Environmental Management: Guidelines for Museums and Galleries, Routledge: London, 1995; pp. 1-160.

19. Bacci, M.; Cucci, C.; Dupont, A.-L.; Gerlach, S.; Lavédrine, B.; Loisel, C.; Martin, G.; Roemich, H. LightCheck ${ }^{\circledR}$, new disposable indicators for monitoring lighting conditions in museums, in: ICOM Committee for Conservation, $14^{\text {th }}$ Triennial Meeting, The Hague, The Nederlands 12-16 September 2005; James and James: London, 2005; Vol II, pp.569-573.

20. Feller. R.L. Use of the International Standards Organization's blue-wool standards for exposure to light. I. Use as an integrated light monitor for illumination under museum conditions, in: Preprints of $6^{\text {th }}$ Annual Meeting of the American Institute for Conservation, Fort Worth, Texas; AIC: Washington, DC, 1978; pp. 73-80.

21. Feller, R. L.; Johnston-Feller, R. M., Use of the International Standards Organization's blue-wool standards for exposure to light. II. Instrumental measurement of fading. In Preprints of Papers $7^{\text {th }}$ Annual Meeting of the American Institute for Conservation, Fort Worth, Texas; AIC: Washington, DC, 1979.

22. Bullock, L.; Saunders, D. Measurement of cumulative exposure using Blue Wool standards, in Preprints triennial meeting (12th), Lyon, 29 August-3 September 1999; James \& James: London, UK, 1999; Vol. 1, pp. 21-26.

23. Camuffo, D. Microclimate for Cultural Heritage; Elsevier: Amsterdam, 1998; pp. 235-292.

24. IAP Copenhagen 2001- $4^{\text {th }}$ Meeting of the Indoor Air Pollution Working Group - On-line Proceedings: http://iaq.dk/iap/iap2001/iap2001.pdf.

25. EC funded Project Contract. n. EVK-CT-2002-00093 - http://www.nilu.no/master/

26. Drdácký, M.; Chapuis, M., Eds. Safeguarded cultural heritage: understanding and viability for the enlarged Europe : Proc. of the $7^{\text {th }}$ European Conference "Sauveur", 31 May - 3 June 2006, Prague; ITAM: Praha, 2007; pp. 41-50.

27. Dahlin, E.; Grontoft, T.; Rentmeister, S.; Calnan, C.; Czop, J.; Hallett, K.; Howell, D.; Pitzen, C.; Sommer Larsen, A. Development of an early warning sensor for assessing deterioration of organic materials indoor in museums, historic buildings and archives. In: ICOM Committee for Conservation, 14th Triennial Meeting, The Hague, 12-16 September 2005: Preprints; James and James: London, 2005; Vol II, pp. 617-624.

28. Espié, L.; Aucouturier, M. Surface modification issues in art. Rev. Métallurg.- Sci. Gén. Matér. 2001, 751-766.

29. Johansson, E.; Leygraf, C.; Rendahl, B. Characterisation of corrosivity in indoor atmospheres with different metals and evaluation techniques. Brit. Corros. J. (UK) 1998, 33, 59-66.

30. La Gennusa, M.; Rizzo G.; Scaccianoce, G.; Nicoletti F. Control of indoor environments in heritage buildings: experimental measurements in an old Italian museum and proposal of a methodology. J. Cult. Herit. 2005, 6, 147-155.

31. EC funded Project Contract CRAFT n. 018207. http://www.corrlog.com. 
32. Prosek, T.; Kouril, M.; Hilbert, L. R.; Degres, Y.; Blazek, V.; Thierry, D.; Hansen, M. Ø. Real time corrosion monitoring in the atmosphere using automated battery-driven corrosion loggers, NKM 14 - 14 ${ }^{\text {th }}$ Nordic Corrosion Congress - Copenhagen, May 2007.

33. IAQ2006 - The $7^{\text {th }}$ Indoor Air Quality 2006 Meeting - On-line Proceedings: http://iaq.dk/iap/iaq2006/Prosek_IAQ2006.pdf.

34. Carmona, N.; Herrero, E.; Llopis, J.; Villegas, M.A. Chemical sol-gel based sensors for evaluation of environmental humidity. Sens. Actuat. B 2007, 126, 455-460.

35. Martellucci, S.; Chester, A. N.; Mignani, A. G. Optical Sensors and Microsystems: New Concepts, Materials, Technologies; Kluwer Academic/Plenum Publisher: New York, 2000.

36. Zaremba, K. Optical fiber lighting system for the miniature painting exposition in the National Museum in Warsaw. In Optical Fibers: Technology; Rayss, J.; Culshaw, B.; Mignani, A. G., Eds.; Proc. SPIE, 2005, 5952, 424-429.

37. Fabbri, M.; Picollo, M.; Porcinai, S.; Bacci, M. Mid-Infrared Fiber-Optics Reflectance Spectroscopy: A Noninvasive Technique for Remote Analysis of Painted Layers. Part I: Technical Setup. Appl. Spectrosc. 2001, 55, 420-427.

38. Ruiz-Moreno, S.; Pérez-Pueyo, R.; Gabaldón, A.; Soneira, M.-J.; Sandalinas, C. Raman Laser fibre optic strategy for non-destructive pigment analysis. Identification of a new yellow pigment (Pb, Sn, Sb) from the Italian XVII century painting. J. Cult. Herit., Lasers in the Conservation of Artworks - LACONA IV 2003, 4(1), 309-313.

39. Bacci, M. Fiber-optics applications to works of art. Sensors Actuat. B 1995, 29, 190-196.

40. Leona, M.; Winter, J. Fiber Optics Reflectance Spectroscopy: A Unique Tool for the Investigation of Japanese Paintings. Stud. Conserv. 2001, 46, 153-162.

41. Mignani, A. G.; Bacci, M.; Trono, C.; Mencaglia, A. Optical Fiber Sensors for the Cultural Heritage. In: Optical Sensors and Microsystems, Part II, Springer SU: Berlin, 2002; pp. 253-258.

42. de La Rie, E. R. The influence of varnishes on appearance of paintings. Stud. Conserv. 1987, 32, 1-13.

43. Mignani, A.G.; Falciai, R.; Trono, C.; Tiribilli, B. Optical fibers for the cultural heritage II: The Monitoring of lighting in Museums Environments. In: Proc. of the $13^{\text {th }}$ International Conference on Optical Fiber Sensors - OFS-13 - April 1999 Kyongju, Korea. Proc. SPIE 1999, 3746, 183186

44. Bacci, M. ; Cucci, C.; Mencaglia, A. A.; Porcinai, S.; Mignani, A.G. Optical fibers for safer exhibition conditions in museums: the measurements of equivalent light dose. In: Optical Metrology for Arts and Multimedia; Salimbeni, R., Ed.; Proc. SPIE 2003, 5146, 170-174.

45. Aldovrandi, A.; Castelli, C.; Matteini, M.; Moles, A. Un metodo di rilevazione delle variazioni dimensionali dei supporti lignei. In: OPD Restauro, n.1; Opus Libri Pub.: Firenze, 1986.

46. Knight, B.; Thickett, D. Determination of response rates of wooden objects to fluctuating relative humidity in historic properties. In: Museum Microclimates Proc. Conference Copenhagen 19-23 Nov. 2007, Padfield, T.; Borchersen, K., Eds.; National Museum of Denmark: Copenhague, 2007; pp. 85-88.

47. Falciai, R.; Trono, C.; Lanterna, G.; Castelli, C. Continuous monitoring of wooden works of art using fiber Bragg sensors. J. Cult. Herit. 2003, 4, 285-290.

(C) 2008 by MDPI (http://www.mdpi.org). Reproduction is permitted for non-commercial purposes. 